\title{
MIMOSINE - A NOVEL SUBSTANCE AND EVALUATE THE LIPID PEROXIDATION
}

\author{
DHANYA K G ${ }^{1 *}$, THANGAVEL $\mathbf{M}^{2}$ \\ ${ }^{1}$ Department of Microbiology, Research and Development Centre, Bharathiar University, Coimbatore, Tamil Nadu, India. ${ }^{2}$ Department of \\ Microbiology, Sree Narayana Guru College, Bharathiar University, Coimbatore, Tamil Nadu, India. Email: kgdhanya23@gmail.com
}

Received: 19 October 2017, Revised and Accepted: 31 January 2019

ABSTRACT

Objective: The mimosine is a novel substance extracted and purified from Mimosa pudica. The present study is to evaluate lipid peroxidation (LPO).

Methods: The sox halation is used to differentiate extracts. Mimosine is purified by gas chromatography-mass spectrometry (GC-MS) and liquid chromatography-mass spectrometry (LC-MS). The present study was conducted to evaluate the hepatoprotective activity of ethanol extract of M. pudica against alcohol-induced albino rats. This was evident from significant of M. pudica on LPO and antioxidants liver of rats.

Results: By GC-MS and LC-MS, the mimosine is purified and it shows the highest peak. The phytochemical analysis of M. pudica and the activity of the enzyme antioxidants such as superoxide dismutase is $176.83 \mathrm{~g}$ and peroxidase is $0.989 \mathrm{~g}$, were found to be present in the plant extract of $M$. pudica. In rat treated with toxic dose of alcohol, a significant increase in serum and liver were observed. Simultaneous oral administration of the aqueous extract of M. pudica reduced the lactate dehydrogenase (LDH) activity to a significant extent compared to control. LDH, a cytosolic liver marker enzyme, is a regulator of many biochemical reactions in the body tissues and the fluid.

Conclusion: The result obtained in our work, existence of bioactive substance proves that it is mainly used as a traditional medicine. The phytochemical analysis indicated the presence of alkaloids, steroids, terpenoids, tannin, phenolic, saponins, proteins, and amino acids. The liver showed that the induction of alcohol causes hepatic necrosis and injury, but it is cured by M. pudica.

Keywords: Mimosa pudica, Gas chromatography-mass spectrometry, Liquid chromatography-mass spectrometry, Mimosine, Liver homogenate.

(c) 2019 The Authors. Published by Innovare Academic Sciences Pvt Ltd. This is an open access article under the CC BY license (http://creativecommons. org/licenses/by/4. 0/) DOI: http://dx.doi.org/10.22159/ajpcr.2019.v12i3.22812

\section{INTRODUCTION}

Mimosa pudica indicated the presence of alkaloids, carbohydrates, steroids, flavonoids, glycosides, turpinoids, phenols, tannins, saponins, coumarin, C-glycosylflavones, gums, and mucilages. It possesses a high microbial and antifungal activity which also reduce headache [1-3]. M. pudica has been reported to contain mimosine (an alkaloid), free amino acid, sitosterol, linoleic acid, and oleic acid. For medicinal benefits, several plants have been identified as a foundation of various effective and prevalent medicines. From the period of the ancient times until today, these herbs used as traditional medications, have been widespread, and have proved to be efficient in curing diseases across the world. It has been demonstrated that in vitro screening techniques may possibly give the required prime perceptions that have been important in selecting crude plant extracts with conceivably valuable characteristics for further chemical, microbiological, and pharmacological examinations. The number of medicinal preparations has been advocated in tradition system of medicine, especially in Ayurveda for treating liver disorders [4-8].

Hepatic cell injury caused by various toxicants such as chemotherapeutic agents, antituberculosis drugs, carbon tetrachloride, paracetamol, chronic alcohol consumption, and pathogenic microbes is well reported [9-11]. People are finding and exploring the advantages associated with herbal contraceptives due to their lower side effects. Herbal contraceptives have lower cost of development as compared to modern medicine. This review explores the recent advances in development that offers many benefits for shifting the paradigm for herbal contraceptives [12-15]. From times, immemorial, references have been made for the plants that possess antifertility properties also [16-19].

\section{MATERIALS AND METHODS}

Materials

M. pudica were taken from Agricultural University, Thrissur, and the mimosine is purified from Sapala Organics, Hyderabad, and lipid peroxidation (LPO) studies were done in Amala Medical College, Thrissur, Kerala.

\section{Preparation of extract}

The coarsely powdered leaves ( $300 \mathrm{~g}$ ) of $M$. pudica were extracted to exhaustion in a Soxhlet apparatus at $50^{\circ} \mathrm{C}$ with $500 \mathrm{ml}$ of ethanol and methanol separately. The extract was filtered through a cotton plug, followed by Whatman filter paper and then concentrated using a rotary evaporator at a low temperature $\left(40-60^{\circ} \mathrm{C}\right)$ and reduced pressure to provide ethanolic and methanol extractive of $8.20 \mathrm{~g}$ separately.

\section{Preliminary phytochemical analysis}

The ethanolic extract and methanol extract of $M$. pudica was subjected to identify the presence of various phytoconstituents, namely alkaloids (Mayer's test), steroids and terpenoids (Liebermann-Burchard test), glycosides (modified Borntrager's test), tannin and phenolic compounds (ferric chloride test), flavonoids (lead acetate test), saponins (foam test), and proteins and amino acids (Xanthoproteic test).

\section{Extraction of mimosine}

The fresh mimosa leaves of $M$. pudica were washed then heated at $100^{\circ} \mathrm{C}$ for $3 \mathrm{~min}$. After that, it was grinded and extracted; then, filtered extract juice was separated and purified extract was freeze dried and purified by gas chromatography-mass spectrometry (GC-MS) and liquid chromatography-mass spectrometry (LC-MS) procedures. 
$G C-M S$

Analysis was carried out on an HP 5890 GC system, coupled to an HP MD 5973 quadruple mass spectrometer. The compounds were separated on an HP-5MS capillary column $(30 \mathrm{~m}, 0.25 \mathrm{~mm}$ i.d., $0.25 \mathrm{~mm}$ film); split injection was used for both samples: The split a ratio was $20: 1$. The column oven temperature was maintained at $40^{\circ} \mathrm{C}$ for $1 \mathrm{~min}$ after injection.

\section{$L C-M S$}

The LC is used in LC-MS and it is combination of high-performance LC (HPLC) with MS. The principle of separation in HPLC or LC-MS is normal phase mode or reverse phase mode of adsorption. Normal phase constricts with polar stationary phase and with non-polar solvent or mobile phase and reverse phase constricts with non-polar stationary phase and with polar solvent/mobile phase LC-MS were conducted using ultra-performance LC system. Chromatographic separation was achieved using HPLC column $(100 \mathrm{~mm} \times 4.6 \mathrm{~mm}, 3 \mu \mathrm{m}$ with a gradient system consisting of $10 \mathrm{~mm}$ ammonium acetate with $0.001 \%$ formic acid. The initial mobile phase which contains $15 \%$ of methanol which was increased linearly to $76 \%$ after $11 \mathrm{~min}$, then decreased back to the initial mobile phase. After 11.6 min and held for $3.4 \mathrm{~min}$ to reequilibrate the LC column, total chromatographic run

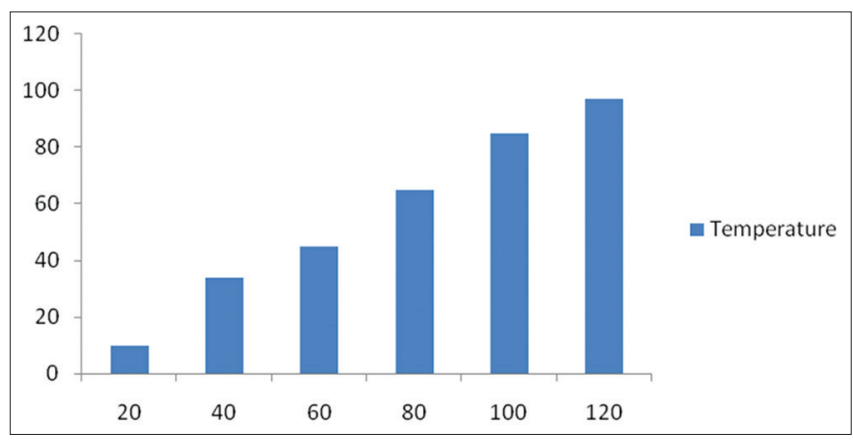

Fig. 1: Effect of temperature on mimosine time was 15 min. Retention time for each analyte was calculated in the software.

\section{Characterization of mimosine \\ Effect of $p H$}

The fresh purified mimosine was dissolved in buffers of different $\mathrm{pH}$ value ranging from 1.5 to 9.0 so that the final concentration of mimosine is equal to $8 \mu \mathrm{M} / \mathrm{L}$, and this mimosine solutions at room temperature for $12 \mathrm{~h}$ after that see the readings of $\mathrm{pH}[20]$.

\section{Effect of temperature}

The fresh purified mimosine was dissolved buffers so that the concentration of mimosine in the buffers is equal to $8 \mu \mathrm{M} / \mathrm{L}$, and this mimosine solution was placed in thermoregulator at 30, 40, 50, 60, 70, 80,90 , and $100^{\circ} \mathrm{C}$ for $2 \mathrm{~h}$

\section{Assessment of liver function}

Blood was collected from all the groups by puncturing the retro-orbital plexus and could clot at room temperature, and serum was separated by centrifugation at $2500 \mathrm{rpm}$ for $10 \mathrm{~min}$. The serum was used for the estimation of biochemical parameters to determine the functional state of the liver.

Table 1: Phytochemical analysis of M. pudica

\begin{tabular}{llll}
\hline S. No & Phytochemicals & Ethanol & Methanol \\
\hline 1 & Alkaloids & $+\mathrm{ve}$ & $+\mathrm{ve}$ \\
2 & Steroids & $+\mathrm{ve}$ & $-\mathrm{ve}$ \\
3 & Terpenoids & $+\mathrm{ve}$ & $+\mathrm{ve}$ \\
4 & Glycosides & $-\mathrm{ve}$ & $-\mathrm{ve}$ \\
5 & Tannins & $+\mathrm{ve}$ & $+\mathrm{ve}$ \\
6 & Phenolic & $+\mathrm{ve}$ & $+\mathrm{ve}$ \\
7 & Flavonoids & $+\mathrm{ve}$ & $+\mathrm{ve}$ \\
8 & Saponins & $-\mathrm{ve}$ & $-\mathrm{ve}$ \\
9 & Proteins and amino acids & $+\mathrm{ve}$ & $+\mathrm{ve}$ \\
\hline
\end{tabular}

M. pudica: Mimosa pudica, +ve: Positive, -ve: Negative

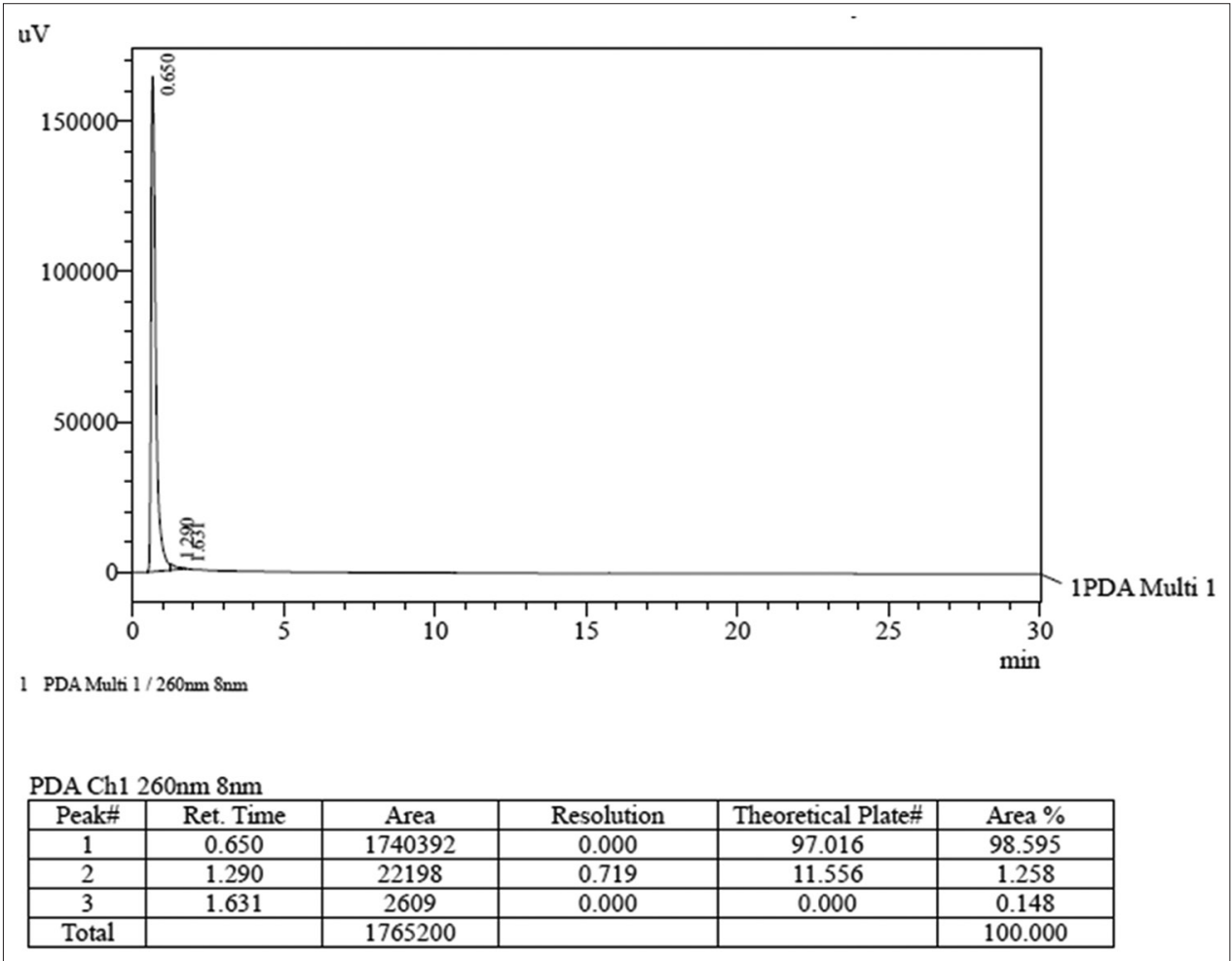

Fig. 2: Liquid chromatography-mass spectrometry analysis graph of Mimosa pudica leaves 
Table 2: Effect of M. pudica on LPO and antioxidants in liver of rats

\begin{tabular}{lllll}
\hline S. No & Parameter & Group I & Group II & Group III \\
\hline 1 & SOD units & $6.324 \pm 0.05$ & $4.432 \pm 0.04$ & $6.246 \pm 0.04$ \\
2 & CAT units & $92.12 \pm 0.46$ & $62.32 \pm 0.55$ & $72.32 \pm 0.51$ \\
3 & GPx units & $4.32 \pm 0.05$ & $3.31 \pm 0.09$ & $3.316 \pm 0.09$ \\
4 & GST units & $1.632 \pm 0.04$ & $2.732 \pm 0.05$ & $2.32 \pm 0.15$ \\
5 & Reduced GSH (nmol/g tissue) & $62.32 \pm 0.55$ & $43.32 \pm 0.59$ & $47.72 \pm 0.59$ \\
6 & Vitamin-C (mg/g tissue) & $0.832 \pm 0.55$ & $0.32 \pm 0.64$ & $1.832 \pm 0.09$ \\
7 & LPO (nmol of MDA/g tissues) & $1.32 \pm 0.55$ & $1.92 \pm 0.56$ & $0.52 \pm 0.64$ \\
\hline
\end{tabular}

M. pudica: Mimosa pudica, SOD: Superoxide dismutase, CAT: Catalase, GPx: Glutathione peroxidase, GST: Glutathione-S peroxidase, GSH: Glutathione, LPO: Lipid peroxidation, MDA: Malondialdehyde

\section{Toxicity studies}

Healthy Wistar albino rats of either sex weighing 150-200 g maintained under standard laboratory conditions were used for acute oral toxicity test per Organization for Economic Cooperation and Development guidelines 423 (OECD, 1996) [21]. Male albino Wistar rats of body weight $150 \mathrm{~g}$ were obtained from Amala Medical College, Thrissur. The rat was housed in large spacious cages and was fed on standard pellet diet and water ad libitum. The animals were well-ventilated area. The experimental procedures were carried out as per strictly animal ethics committee's rules and regulations of this institute.

\section{RESULTS}

By GC-MS and LC-MS, the mimosine is purified and it shows highest peak (Fig. 1). The mimosine temperature and $\mathrm{PH}$ is shown in Figs. 2 and 3. The phytochemical analysis of M. pudica (Table 1) and the activity of the enzyme antioxidants such as superoxide dismutase (SOD) is $176.83 \mathrm{~g}$ and peroxidase is $0.989 \mathrm{~g}$, were found to be present in the plant extract of M. pudica. In rat treated with toxic dose of alcohol, a significant increase in serum and liver were observed. Simultaneous oral administration of the aqueous extract of $M$. pudica reduced the lactate dehydrogenase (LDH) activity to a significant extent compared to controlled; a cytosolic liver marker enzyme is a regulator of many biochemical reaction in the body tissues and the fluid.

\section{Hepatoprotective efficacy of M. pudica}

The present study on the hepatoprotective efficacy of M. pudica on ethanol-induced liver damage in rats was carried out, and carried out and results obtained are discussed (Fig. 4). The activity of the enzyme antioxidants such as SOD is $176.83 \mathrm{~g}$ and peroxidase is $0.989 \mathrm{~g}$, was found to be present in the plant extract of $M$. pudica. Non-enzymatic antioxidants, such as phenols are $27.63 \mathrm{~g}$, flavonoids are $0.436 \mathrm{~g}$, reduced glutathione (GSH) is $216.19 \mathrm{~g}$, Vitamin-E is $179.81 \mathrm{~g}$, and tannins are $87.678 \mathrm{~g}$, were analyzed in the aqueous extract of $M$. pudica.

\section{LPO}

The activity of the enzyme antioxidants such as SOD, peroxidase, catalase (CAT), and polyphenol oxidase was found to be present in the plant extract of $M$. pudica. Non-enzymatic antioxidants such as phenols, flavonoids, carotenoids, reduced GSH, ascorbic acid, $\alpha$-tocopherol, and total proteins were analyzed in the aqueous extract of $M$. pudica. In rat treated with toxic dose of alcohol, a significant increase in serum and liver were observed. Simultaneous oral administration of the aqueous extract of M. pudica reduced the LDH activity to a significant extent compared to control. LDH, a cytosolic liver marker enzyme, is a regulator of many biochemical reactions in the body tissues and the fluid. Disturbances in cell membrane were estimated by measuring the leakage of LDH. A significant reduction in the activity of antioxidant enzyme such as SOD and CAT were observed in rats intoxicated with alcohol (Group II), but coadministration with M. pudica activity according to below Table 2 .

\section{DISCUSSION}

Phytochemical exhibits wide range of biological effects as constituents at their antioxidant properties [22-24]. The phytochemical analysis of the crude extract indicated the presence of alkaloids, glycosides,

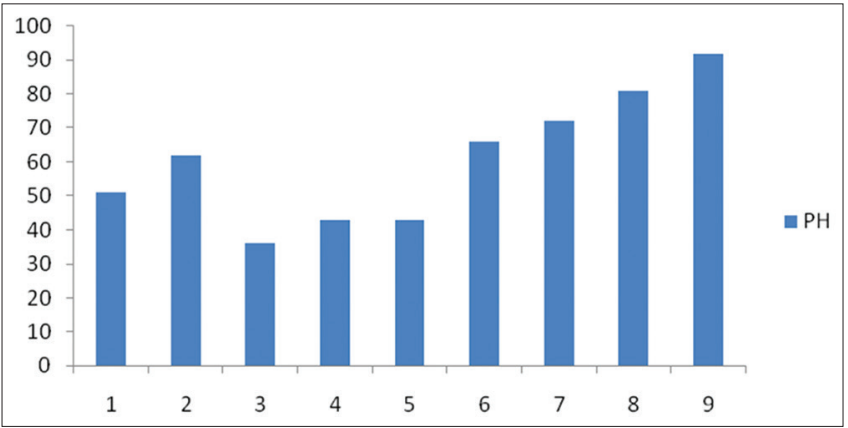

Fig. 3: Effect of pH on mimosine

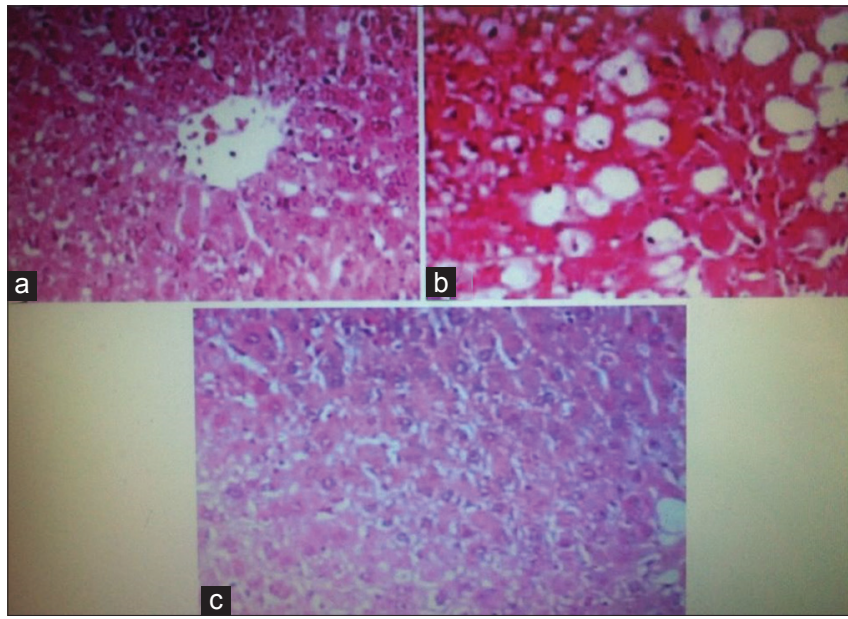

Fig. 4: Hepatoprotective activity: (a) Normal hepatic architecture (b) Alcohol control - hepatic necrosis, (c) Cell regeneration

tannins, proteins, amino acids, and steroids. These compounds are known to be biological active and, therefore, aid the antimicrobial activity. The liver showed that the induction of alcohol causes hepatic necrosis and injury.

\section{CONCLUSION}

It can be aided that the ethanol extract of M. pudica exhibited a hepatoprotective effect induced hepatotoxicity [25-27]. Efforts are in progress to isolate and characterize the active principle, which is responsible for the hepatoprotective efficacy of this valuable medicinal plant. Histopathological observation also supported the above findings. The liver showed that the induction of alcohol causes hepatic necrosis and injury. The recovery of clinical symptoms is possible attributable to the regenerating effect of $M$. pudica extract.

\section{ACKNOWLEDGMENT}

I am grateful to our research supervisor for helping and giving support, Sapala Organics, Hyderabad, and Amala Medical College, Thrissur, 
for providing infrastructure and resources to carry out our research project.

\section{AUTHORS' CONTRIBUTIONS}

Both the authors contributed equally in protocol preparation, ethical approval, content of the experiment, data collection, analysis, and manuscript preparation.

\section{CONFLICTS OF INTEREST}

There are no conflicts of interest.

\section{REFERENCES}

1. Kuppusamy KS. Siddha maruthuvam Inc. Indian Med Homeopathy 2012; 8:584.

2. Mudaliyar KS. Materia medica (vegetable section), Inc. Indian Med Homeopathy 2013;1:551.

3. Lakshmi N, Sasikumar M, Sunita S, Manisha B, Ramesh S. Reversedphase high-performance thin-layer chromatographic quantification of mimosine from the whole plant of Mimosa pudica. Int J Pharm Chem 2007;20:49-51.

4. Zhang ZG, Wu L, Wang JL, Yang JD, Zhang J, Zhang J, et al. Astragaloside IV prevents MPP-induced SH-SY5Y cell death via the inhibition of bax-mediated pathways and ROS production. Mol Cell Biochem 2012;364:209-16.

5. Suzuki K, Mizuno Y, Yoshida M. Effects of 1-methyl-4-phenyl1,2,3,6-tetrahydropyridine (MPTP)-like compounds on mitochondrial respiration. Adv Neurol 1990;53:215-8.

6. Smeyne RJ, Jackson-Lewis V. The MPTP model of Parkinson's disease. Brain Res Mol Brain Res 2005;134:57-66.

7. Kshema J, Gopinathan N, Chitra K. Mimosa pudica Linn-a shyness princess: A review of its plant movement, active constituents, uses and pharmacological activity. Int J Pharm Sci Res 2014;5:5104-18.

8. Ahmad H, Sehgal S, Mishra A, Gupta R. Mimosa pudica L. (Laajvanti): An overview. Pharmacogn Rev 2012;6:115-24.

9. Sibi PI, Delphia PG. Nootropic studies of ethanolic extract of Mimosa pudica Linn. In albino wistar rats. Am J Phytomed Clin Ther 2013; 3:266-75.

10. Patro G, Kumar Bhattamisra S, Kumar Mohanty B. Effects of Mimosa pudica L. Leaves extract on anxiety, depression and memory. Avicenna J Phytomed 2016;6:696-710.

11. Lv C, Hong T, Yang Z, Zhang Y, Wang L, Dong M, et al. Effect of quercetin in the 1-methyl-4-phenyl-1, 2, 3, 6-tetrahydropyridine- induced mouse model of Parkinson's disease. Evid Based Complement Alternat Med 2012;2012:928643.

12. Krishnan P. The scientific study of herbal wound healing therapies: Current state of play. Curr Anaesthesia Crit Care 2006;17:21-7.

13. Okuno Y, Nakamura-Ishizu A, Kishi K, Suda T, Kubota Y. Bone marrow-derived cells serve as proangiogenic macrophages but not endothelial cells in wound healing. Blood 2011;117:5264-72.

13. Macleod J, editor. Davidson's Principle and Practice of Medicine. $13^{\text {th }}$ ed. Edinburgh UK: Churchill Livingstone; 1981. p. 590-2

15. Li J, Chen J, Kirsner R. Pathophysiology of acute wound healing. Clin Dermatol 2007;25:9-18.

16. Wahl LM, Wahl SM. Inflammation. In: Cohen IK, Diegelman RF, Lindblad WJ, editors. Wound Healing: Biochemical and Clinical Aspects. Philadelphia, PA: W.B. Saunders; 1992. p. 40-62.

17. Stadelmann WK, Digenis AG, Tobin GR. Physiology and healing dynamics of chronic cutaneous wounds. Am J Surg 1998;176:26S-38.

18. Srividhya P. Siddha pharmacopoeia of India; (1973). p. 30-1.

19. Cuzzell JZ, Stotts NA. Wound care. Trial and error yields to knowledge. Am J Nurs 1990;90:53-60, 63

20. Wu CR, Tsai CW, Chang SW, Lin CY, Huang LC, Tsai CW, et al. Carnosic acid protects against 6-hydroxydopamine-induced neurotoxicity in in vivo and in vitro model of Parkinson's disease: Involvement of antioxidative enzymes induction. Chem Biol Interact 2015; 225:40-6.

21. OECD. Guidance Document on the Recognition, Assessment and Use of Clinical Signs as Humane Endpoints for Experimental Animals Used in Safety Evaluation environmental Health and Safety Monograph Series on Testing and Assessment No 19; 2001.

22. Hanna JR, Giacopelli JA. A review of wound healing and wound dressing products. J Foot Ankle Surg 1997;36:2-14.

23. Albritton JS. Complications of wound repair. Clin Podiatr Med Surg 1991; 8:773-85.

24. Rosen JS, Cleary JE. Surgical management of wounds. Clin Podiatr Med Surg 1991;8:891-907.

25. Sabogal-Guáqueta AM, Muñoz-Manco JI, Ramírez-Pineda JR, Lamprea-Rodriguez M, Osorio E, Cardona-Gómez GP, et al. The flavonoid quercetin ameliorates Alzheimer's disease pathology and protects cognitive and emotional function in aged triple transgenic Alzheimer's disease model mice. Neuropharmacology 2015;93:134-45.

26. Senthil Kumar M, Sripriya R, Vijaya Raghavan H, Sehgal PK. Wound healing potential of Cassia fistula on infected albino rat model. J Surg Res 2006;131:283-9.

27. LaVan FB, Hunt TK. Oxygen and wound healing. Clin Plast Surg 1990; $17: 463-72$ 